\title{
Right to Play for Children with Disabilities
}

\author{
Julia Mulder, Mikaela Graf, and Samantha Carter \\ Undergraduate Students, Program in Childhood and Youth Studies \\ Carleton University, Ottawa, ON
}

\begin{abstract}
The following research study seeks to examine problematic discourses around children with disabilities and their right to play, through a critical disability studies and children's rights lens. This paper will argue that inadequate understandings of children's varied definitions of play can lead to exclusion in non-institutional and institutional settings. Through the use of photovoice and interview analysis, we sought to take a holistic approach to understanding the varied ways children with disabilities, and educational assistants, answered questions surrounding "what is play?" Our findings align with the notion that the right of children with disabilities to play is complex and interdisciplinary. Bridging access to cultivate appropriate inclusion through awareness, applicable school programming, and a redefined definition and discourse around play, is crucial for children to authentically participate in their version of play, as defined by themselves. Valuing children's full right to play, as defined by the UNCRC, allows for a greater understanding of the social and political complexities of working with children instead of challenging their ability to advocate for themselves.
\end{abstract}


The ability to understand and implement the rights of all children is crucial to working with children. Children's rights are frequently overlooked, which results in the further suppression of rights for children with disabilities. Building upon this knowledge is crucial not only to recognizing children as people, but also to empowering and educating them about their rights.

The United Nations Convention on the Rights of the Child (UNCRC) outlines various rights that children possess; however, the explanations are vague in construction. Article 31 of the UNCRC defines the right to play as: "the right of the child to rest and leisure, to engage in play and recreational activities appropriate to the age of the child and to participate freely in cultural life and the arts" (OHCHR, 2002, p. 9). This definition excludes consideration of the different forms of play that children may engage in. The UNCRC's assumption that play must be "age-appropriate" is problematic when reflecting upon the mental versus chronological age of children at play. Developmental psychology approaches focus on "typical" stages of development, considering age and a child's respective abilities. This model applies a linear model of cross-childhood development to children with disabilities, neglecting to consider the interdisciplinary nature of childhoods. Critical disability studies contest the exclusions of a linear model of development, by moving towards inclusion through authentically listening to the voices and experiences of children with disabilities (Curran \& Runswick-Cole, 2014).

For our paper, play will be defined as "a dynamic, active, and constructive behaviour, considered from a variety of perspectives - theoretical, parental, and childhoods. Play can be both socially and cognitively beneficial to children's development" (Glenn, Knight, Holt, \& Spence, 2012). This definition allows for a better understanding of the various perspectives of development that can shape children's innate right to play. The objective of this article is to improve advocacy and to gain a better understanding of children with disabilities and their right to play. Identifying the legal right to play as more accessible for certain bodies, as opposed to others, increases the urgency for greater advocacy.

We attempt to uncover issues surrounding play for children with disabilities and to redefine play throughout our research collection and literature review. In identifying and challenging inequality, it is crucial to focus on the voices and experiences of children while considering the role of play intervention (Curran \& Runswick-Cole, 2014). This paper will take a person-first language approach of "children with disabilities," to support the rights-based 
approach, focusing on the child. We identify four key themes from our research: a lack of awareness surrounding a rights-based approach to childhoods, a lack of inclusion in play for these children, the importance of programming, and the need for a redefinition of play. From a childhood studies and critical disability studies perspective, we argue that inadequate understandings of children's varied definitions of play lead to exclusion in institutional and noninstitutional settings.

\section{Literature Review}

The UNCRC states that children have an innate right to play; however, this right is often suppressed or neglected, including in children with disabilities (OHCHR, 2002). Recall that the UNCRC definition of the right to play does not account for the different experiences of children. Play is both socially and cognitively beneficial, as well as dynamic and constructive. The following analysis of previous research allows for greater contributions to the field of play, which will shape how we analyze our research findings in the context of children with disabilities and their definitions of play.

Play has an essential role in helping children to understand their world through working and doing, which is often limited by the use of developmental perspectives. Glenn, Knight, Holt $\&$ Spence consider that "play is not only a quintessential childhood activity but has also been described as the most important 'work' of being a child"' (p. 186). However, developmental perspectives exclude diverse definitions and understandings of play. Lev Vygotsky defines development as "a progression of qualitative changes marking the transitions from one age period to another" (Bodrova, 1997). These "transitions," defined by Bodrova (1997), are understood through high or low mental capacities. Once children can accomplish a high level of learning, according to developmental theorists, they become masters of their behaviour, yet some may never achieve this stereotyped standard (Bodrova, 1997). This ideology lacks an understanding that childhood does not have one single definition, and it creates a hierarchy that classifies a societally determined definition of appropriate play (Kehily, 2013). Ultimately, Vygotsky's perspective dominates the societal discourses of children with disabilities and limits the environments in which these individuals can engage in play (Goodley \& Runswick-Cole, 2010). Our research will demonstrate that these stereotypes should not be applied to all children with disabilities. 
Play has often been used to teach children ways to socially interact with others in social spaces. The theory of mind is usually seen as significant in understanding children with disabilities in social spaces, as it refers to one's ability to understand the thoughts, beliefs, and desires of another individual (Frith \& Frith, 2005). This social ability is developed through play; therefore, the efforts of educators to facilitate play through in-school intervention are beneficial to a child's social and cognitive development. In contrast, critical disability scholars challenge the developmental approach, which assumes that children with disabilities need to be 'fixed.' For example, McGuire and Michalko (2011) suggest that "rather than treat autism as a puzzle that must be solved, we treat autism as a teacher and thus as having something valuable to contribute" (p. 162). Critical disability studies can be used to enhance our argument that play includes and excludes certain bodies through the ableist ideology that marginalizes difference.

Additionally, the debate over the theory of mind has lacked the involvement of children with disabilities, suggesting that they are not considered as innately social beings, and social skills need to be entirely taught. The theory of mind assumes that children with disabilities have no social skills, and it neglects to consider the different ways in which they are able to be social. Their unique perspectives contribute to a more encompassing understanding of childhood play (McGuire \& Michalko, 2011). Therefore, while the theory of mind has been seen as creating a greater understanding of children with disabilities and their participation in spaces, it narrowly assumes that children with disabilities are incapable of being social, rather than considering the unique perspectives that can be shared by all children.

Research shows a greater engagement in more creative play for autistic children (Bentenuto, De Falco, \& Ventui, 2016). Conversely, Goodley and Runswick-Cole challenge the dominant assumption that children with disabilities are "other," which explains why they play differently compared to children without disabilities. It is important to note that this difference in play can stem from other differences, such as personality and family dynamics (Goodley \& Runswick-Cole, 2010). In our current study, we will use participatory visual methods, including photovoice, to reflect that every child creates their own definition of play. Such methods have been successfully used in other research that encouraged girls with disabilities to understand their experiences (Nguyen, Mitchell, De Lange, \& Fritsch, 2015).

It is essential to provide insight into the context surrounding children with disabilities and their right to play. Our research continues to engage with children with disabilities by drawing on 
their real-life experiences and reflecting on their relationship with educators. We focus on a rights-based approach to understand play for children with disabilities, as we work to include them in discourses that affect their lives. We hope that the following summary of our findings will highlight the importance of this field of research, by considering the implementation of more inclusive spaces for children with disabilities, developing school interventions, and providing the necessary resources in order for children to flourish.

\section{Method}

Participants were sampled from the Ottawa area using word of mouth to attract participants. In total, we recruited two boys aged five and eleven and two female adult participants. We sampled three Caucasian and one Latino participant. One child participant with Attention Deficit Hyperactivity Disorder (ADHD) and behavioural challenges and one autistic child participant were recruited for this research. Consent was obtained from all participants, including the children, after a discussion of the research goals and their roles in our research. Reassurance was required for one of the child participants as he was unsure of participating in the study. After we explained that the participant's role was to provide us with a holistic understanding of play in the lives of children with disabilities, he willingly signed the consent forms.

We used a rights-based approach, whereby the children were seen not only as participants but as creators of their definition of play through photovoice. For our research, we define photovoice as a form of research that allows participants to capture their environments and experiences with a camera (Nguyen et al., 2015). We hoped that allowing children to capture how they define play would promote their right to participation. During the photovoice process, children were asked to take or select two photos of how they define play. Instead of taking the photos himself, one of the child participants selected previously taken photos of how he defined play. This still ensured that his voice was heard as he provided reasons as to why he chose the photos to illustrate his definition.

We also decided to conduct semi-structured interviews with two adults who currently work as educational assistants in the Ottawa-Carleton District School Board and primarily work with children with disabilities. These interviews allowed for a better understanding of play amongst children with disabilities from a different perspective. During the interviews, adults were asked a series of questions relating to their relationship with children with disabilities and 
their experiences with those children and their right to play. Interviews were recorded and transcribed verbatim. Unfortunately, due to technical difficulties, one of the recordings was not able to be transcribed, and field notes were used to conceptualize the overall findings. The data were divided into sections by questions asked and were analyzed by researchers from a rightsbased and child-centred perspective. We analyzed the transcripts and connected the photos taken and selected by the children to build upon the conversation. We found four overall themes that the following section of this paper will develop, by reflecting on photovoice: lack of awareness, inclusion, school programs, and the need for a redefinition of play.

\section{Findings}

\section{Lack of awareness}

Lack of awareness was one of the significant findings that emerged when we analyzed the semi-structured interviews. During one of the interviews, the interviewee asked that we stop recording and explain the meaning of a rights-based approach. This simple request is vital to our research because it demonstrates a lack of educators' awareness of the programs and needs of children with disabilities. Educators must have a clear understanding of the rights-based approach in order to implement programming with children. This same lack of awareness can also influence how the public interacts with and reacts to children with disabilities during public environment play. In particular, autistic children can have a difficult time engaging in certain environments, which sometimes leads to behaviours that are considered socially inappropriate.

Ableist perspectives demonstrate the discrimination towards children with disabilities; the notion of able-bodied superiority assumes that these 'inappropriate' behaviours are unwanted and undesirable and occur with intent to cause harm, rather than a form of self-expression (Goodley \& Runswick-Cole, 2014). One of the interviewees said that "play is often looked at as something that an adult can give and take away as a form of control and punishment" (Interviewee 2, 2019). This finding provides insight into the challenges of seeing children as active in their own development, including play, especially children with disabilities.

Rights-based approaches are essential to the conversation about children's right to play, as they provide insight into the multiple actors involved in facilitating play and the agency that children themselves exhibit during their development. This is shown simply by how our child participants engaged with the photovoice project differently. All submitted pictures that reflected 
their individual understandings of the meaning of play in their lives. However, rights-based scholars support the assumption that children with disabilities need care and protection, but that their maturity is perceived as inadequate for decision-making. This is challenged by critical disability scholars who focus on children with disabilities as having an innate right to involvement in the decisions that influence them (Goodley et al., 2010). Ultimately, these differing perspectives provide insight into developing a better understanding of how to implement inclusive programs.

\section{Inclusion}

The importance of inclusion was another theme that became apparent when we analyzed the interviews. The inclusion of children with disabilities is best thought of as moving away from the perceived constraints of physical, cognitive, and social impairments, to allow children, regardless of age and ability, to participate and give voice to the aspects of their lives that influence them. According to Nguyen (2015), society puts individuals with disabilities through three different 'rescue missions,' further enforcing notions of 'difference.' First, pressure is put on individuals with disabilities to 'get better' or 'overcome' their disability, and resources of rehabilitation are given by society to enforce this ableist notion. Second, through the neo-liberal mode of governance, individuals are taught to become as self-reliant as possible. Lastly, support is given to individuals with disabilities to engage in recreational, educational, and career opportunities, as a form of normalizing and integrating these individuals into society. This process of self-governance is referred to as bio-politics - the complex processes by which institutions exercise forces upon the body, and which shape values and discourses of disability as problems that require normalization and curability (Nguyen, 2015).

While thinking about inclusion, it is therefore important to understand the bio-politics and background that come along with such ideology. As said by Nguyen, "reading inclusion as universal and ahistorical is dangerous, because in so doing, we lose sight of the nuanced and contested nature of historical representations" (Nguyen, 2015, p. 86). Inclusion, therefore, must be considered contextually, along with the needs of those being included.

Supported by empirical research, Interviewee 2 said that play amongst children with disabilities often occurs with objects to support their sensory needs, including the use of assistive technology (Interviewee 2, 2019; Thompson, Shanahan, \& Gordon, 2018). Assistive technology 
gives children with disabilities the opportunity to participate to the extent that they desire, moving away from the dominant discourse of inclusion that often underlies tokenistic participation (Allan, 2002). We define inclusion as the involvement of children in decisions about their own participation and their ability to move within a space, through giving them the resources and voice to do so. Wheelchairs, Picture Exchange Communication Systems, and the Art of Play are a few examples of assistive technologies that work to achieve equitable environments, in such places as classrooms and playgrounds (Visentin, 2018; Agius, 2016). Thus, while assistive technology could be used as a bio-politic of governing the disabled body, we found it interesting that Interviewee 2 seemed to advocate for this approach. She believes that this technology can capitalize on the strengths of students, and build upon the weaknesses (Logan et al., 2017). These forms of technology are not about 'finding a cure' (Clare, 2017) but rather, about building connections between strengths and weaknesses, whether disability is present or not.

Participants also discussed how inclusion and exclusion of children with disabilities functioned through self-directed play. Self-directed play is defined as play in which children are encouraged to engage in their own experiences and follow self-motivated behaviours (ClarkeStewart \& Parke, 2014). For example, the interviewees recognized through their experience on the school board that self-directed play for children with disabilities is often more challenging and must be learned, whereas such play may come more 'naturally' for children without disabilities. This challenge often leads to exclusion, which is detrimental to the development of social skills for children with disabilities, along with a lack of nuanced understanding around self-directed play. Play, therefore, excludes certain bodies from participating in group activities, based on understandings of difference or disability. Gym class is a prime example of how some bodies are excluded from 'play.' While most educational curriculums require students to engage in physical activity, sports are often complex and detail-oriented. Individuals who are limited due to physical and detail-oriented constraints may find it challenging to engage in this form of play. This lack of access shows that ableism is at play. Providing an inclusive and positive environment is vital for children with disabilities regardless of their challenges, as it helps breakdown the fear of difference that is so prevalent in our society.

It is essential to shift from thinking of difference negatively towards thinking about it as a way to learn new things. This shift in inclusive thinking is made by many special educators as a 
way to ensure that the students flourish. Julie Allan, a leading scholar in inclusive education, suggests that becoming inclusive means listening to what children say about their experiences of inclusion. Her critical work considering programs implemented by schools underlines the distinction between inclusion and integration. This distinction considers the need for "special education" as a double-edged notion that often leads to further exclusion (Allan, 2002). It allows further understanding of how to ensure inclusive spaces, rather than the tokenistic inclusion/participation of children with disabilities. Contrary to these goals, ableist perspectives tend to align with the notions of infantilization and the unfavourable comparisons between children with disabilities and children without. Ultimately, inclusion allows for our discussion to challenge normative assumptions and to initiate change.

\section{School programs}

School programs and intervention strategies have become more common in the classroom, such as Art of Play for younger children and Art of Conversation for older children, as brought to our attention through our interviews with educational assistants (Visentin, 2018). For example, one of the interviewees described these programs as "teaching autistic children different ways to engage in play, with or without other students" (Interviewee 2, 2019). Our interview participants have been involved in the implementation of specific play programming for students with whom they work one-on-one. Engaging in play with and without other students is key to building an individual definition of what play means for each person. These programs support the importance of inclusion and joint participation, recognizing the societal and political barriers that inhibit children's ability to engage with their peers, as discourses of assimilation are enforced on children with disabilities (Nguyen, 2015). Providing an environment that is positive and inclusive is essential when considering this demographic and could be made applicable to other demographics as well.

Interestingly, according to Interviewee 1, who works in a classroom setting with children with disabilities, these programs were not implemented consistently in schools, nor did they benefit all children involved. Specifically, although Interviewee 1 believed these programs had positive effects, she also explained how they affect every child differently - having a more positive effect for some. Thus, understanding that these programs do not work in the same ways for every student is vital to furthering our understanding of the role that play has in every 
individual's life. The benefits of these inclusive programs, as illustrated through empirical research, must be critically evaluated to improve their accessibility, inclusiveness, and use. Allan, through her research, suggests a pedagogical shift from creating inclusive individuals to building inclusive environments that include every child (Allan, 2003). Barriers to inclusion are everywhere, including in classroom environments, that have the possibility to become more political in nature.

Another interviewee recognized the importance of "meeting children at their level when implementing new programs" to improve the effectiveness of play for children with disabilities (Interviewee 2, 2019). This recognizes that all children are different and may respond differently to the same intervention, with the same aim being to improve their social skills while fostering their right to play.

\section{Redefining play}

In facilitating the photovoice aspect of our research project, we were able to gain a greater understanding of how play is defined through children's perspectives. Through discussions with the children about their photos, we obtained different characterizations of play. This section will elaborate on the ways in which children with disabilities redefined play through our photovoice project.

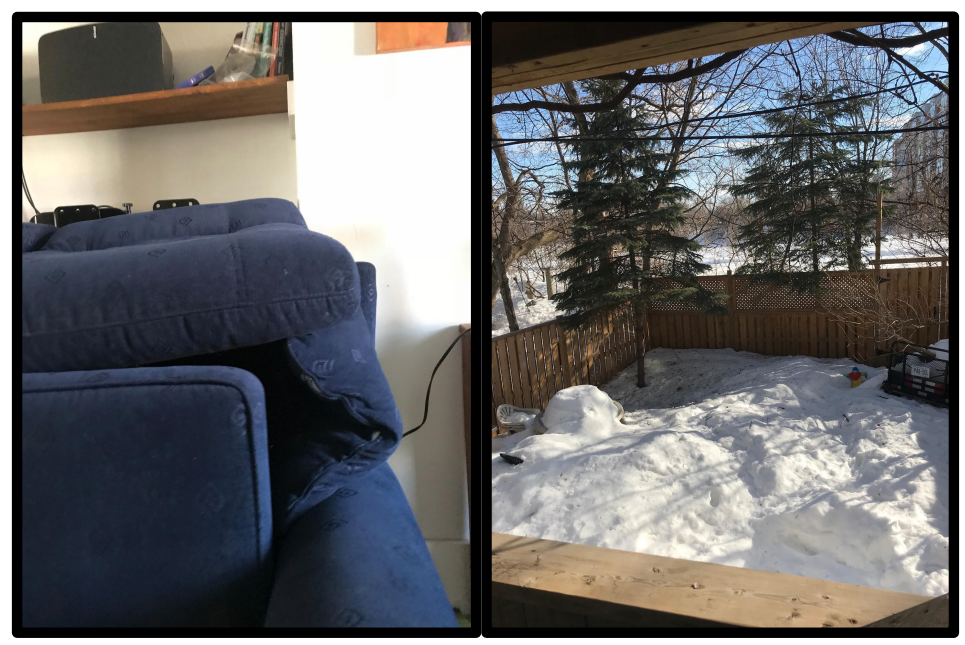

These photos were taken by Participant 1. On the left is a photo of the fort the participant built with his brother. On the right is a photo of his backyard. 
Participant 1 described play as an act of building and being creative. When we arrived to facilitate the photovoice, he was actively engaged in building a fort out of couch cushions, as seen in the photo on the left. A sophisticated, creative narrative about a camping excursion accompanied his interest in planning his design. This is significant as it provides insight into his own definition of play and how his definition supports his creative personality. Using couch cushions in Participant 1's form of play was not a structured form of play with toys, games, or books, but rather play he was able to create with the resources available to him. The way in which the cushions were used also exemplifies his creative ability and insight. For example, building his fort on top of the couch instead of on the floor, or making sure that the fort had a roof. Each detail illustrates part of the participant's creativity in developing his personal definition of play.

The participant also discussed being outside and moving around as an essential aspect of play, in his opinion, to supplement the photo of his backyard. In the case of this child with ADHD, physical activity and tactile forms of learning are critical in his development through play; however, this definition of play would show specific contrasts when applied to a child with a physical disability. Challenges with mobility can alter how a child can play simply through the way that they can engage with and move their bodies. Instead of kicking a soccer ball, these children may be more verbally, socially, or computer program focused. Thinking about play tends to be in correlation with how we have experienced or interacted with play in our own lives. Interestingly, when we asked the participant to take another photo, his reaction was to take a picture of his brother. This simple gesture is crucial as it reflects his agency in defining his play with different social relationships, specifically with his younger brother. It demonstrates the social aspect of play through the participant's desire to include his brother in his definition. Logan et al. (2017) describe the use of toys as a creative way for children with disabilities to develop their voices and action. This is significant because it allows further understanding of different social interactions and relationships that are developed through play. 


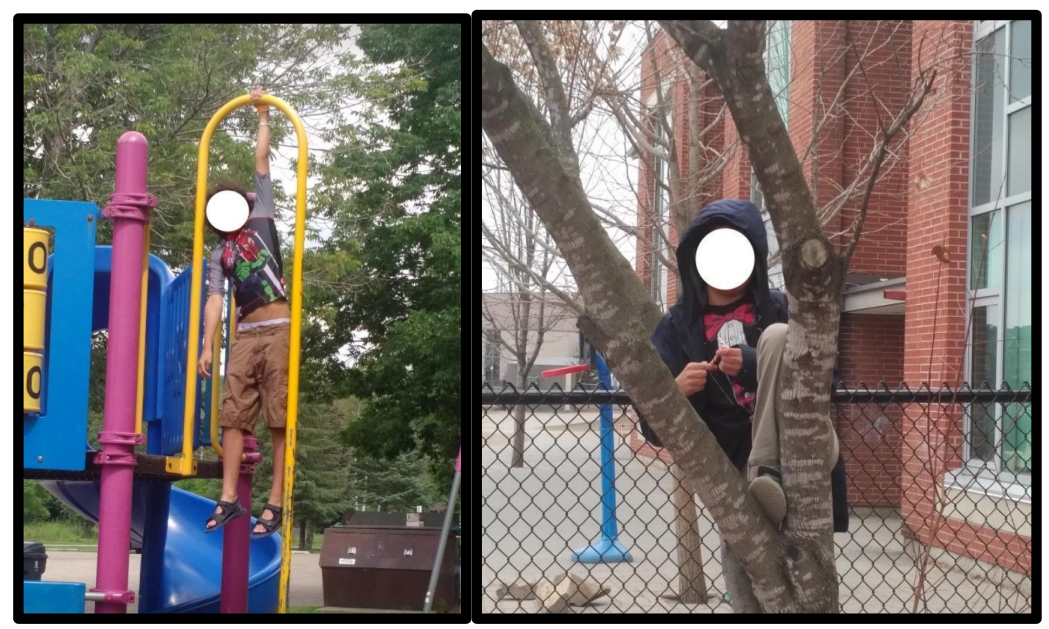

These photos were chosen by Participant 2. The photo on the left was described as "spending time exploring new places like parks to just hanging around on!" The photo on the right was described as "finding things to do by yourself that keep you occupied and entertained."

Participant 2 also discussed play as a social activity, which becomes more accessible through peer-to-peer interactions with siblings and friends. Play is an essential facet for social development. This autistic child recognized the importance of socialization through play, yet other children with disabilities may have varying degrees of social competence and might neglect to think of play in this manner. The participant also noted the unstructured aspects of play, which require him to find new ways to entertain himself. He described how sometimes he needs to "play" while waiting for his parents, creating games as he goes. These are examples of how play does not always need to be structured or planned but can be altered or redefined for the situation and place, becoming less adult-directed and more self-directed. The participant also explained how play sometimes included "doing things that may be a little scary at first, but fun once you've tried it with friends" (Participant 2, 2019). This example shows the need for relationships while engaging in play activities, as discussed previously, and illustrates the everchanging aspects of play.

The characteristic findings between our two participants who completed a photovoice project are that there is not one single definition of play and that we must continuously work with children to help them redefine play for each situation, child, and environment. In working alongside children with disabilities, we must understand how they each hold their own 
understanding of this concept and how they define it. This is important as it provides insight into the ideology of the New Sociology of Childhoods and how there are multiple ways of considering childhoods and play (Kehily, 2013).

\section{Implications}

This children's rights-based perspective allowed us as researchers to advance our understanding of the importance of creating spaces of inclusion, developing awareness, and providing appropriate educational interventions. Our research on the right to play for children with disabilities could inform future school policies and the ways that parents engage in play with their children with disabilities. Through our gained understanding of children's redefinition of play, more inclusive environments can be created in order for children to participate to the fullest extent in their innate right to play. No child should need to fight for this fundamental right, but children with disabilities should especially be given opportunities to flourish in both institutional and non-institutional environments. Children's rights, as previously mentioned in this paper, are often suppressed. Through researching the specific rights of children, the public, including policy-makers, can gain a better understanding of the implications when these rights are not upheld. The emerging importance of researching with children has fostered creativity in the design of educational programming for children with disabilities to develop social competence and self-directed play (Clarke, Flewitt, Hammersly, \& Robb, 2014). Overall, research conducted in this context has the potential to improve public and government understanding of the importance of the right to play for children with disabilities. Our research offers important implications for developing new policies, programming, and inclusion within education and children's everyday lives.

\section{Limitations}

Overall, though our study allowed us to obtain varying understandings of children with disabilities and their right to play, there are limitations to consider before continuing future research. Firstly, our research lacked representation of a variety of disabilities, focusing mainly on autistic children, due to the difficulty of finding participants. For example, this focus excluded children with disabilities that affect mobility. Also, our demographic representation lacked diversity; therefore, we recommend that future research considers a wide variety of cultural and 
ethnic backgrounds. Secondly, our previous relationships with our participants may have created bias in their responses and assumptions in the analysis of these interviews. Due to the time constraints of this research project, we were unable to provide extensive examples of children with disabilities and their varying definitions of play. Future research should continue to expand upon our notion to redefine play, by conducting more photovoice activities with children with mobility, social, and cognitive disabilities, to further develop our valuable research. Lastly, our difficulty in finding participants did not allow for equal gender representation in our study. Our two interviewees were both females, and the child participants were both males. Future research should continue to use a rights-based approach, while keeping in mind the limitations of our study, in order to obtain more conclusive findings surrounding the right to play for children with disabilities.

\section{Conclusion}

Through empirical research and our research contributions, we conclude that the right of children with disabilities to play is complex and interdisciplinary, meaning that the inclusion and consideration of multiple disciplines of study are needed. Play is a part of all children's lives and can be considered the most critical work of being a child (Glenn et al., 2012). Unfortunately, government and educational policies do not consider the implications of children's right to play as innately given to them in the UNCRC (OHCHR, 2002). Building access and awareness, cultivating inclusion, and the application of school programming all benefit both social and cognitive development during this crucial stage of children's early development. Understanding play as interdisciplinary involves thinking about the many actors, including educators, parents, researchers, and children, who have a role in a child's right to play. Finally, for children with disabilities to fully participate in their right to play, they must be given the resources and opportunities necessary to facilitate authentic play, as defined by the children themselves.

\section{Acknowledgements}

We want to thank our participants for taking the time to participate in interviews and photovoice activities, and for helping us understand and conceptualize children with disabilities and their right to play. We would also like to thank Professor Xuan Thuy Nguyen for her support and guidance through this extensive research process. Lastly, we would like to thank Sheila South for aiding us during our recruitment stage of finding child participants. 


\section{References}

Agius, M. \& Vance, M. (2016). A comparison of PECS and iPad to teach requesting to preschoolers with autism spectrum disorder. Augmentative and Alternative Communication. 32(1), 58-68. https://doi.org/10.3109/07434618.2015.1108363

Allan, J. (2003). Productive Pedagogies and the Challenge of Inclusion. British Journal of Special Needs. 30(4).

Bentenuto, A., De Falco, S., \& Ventui, P. (2016). Mother-Child Play: A Comparison of Autism Spectrum Disorder, Syndrome, and Typical Development. Frontiers in Psychology.

Retrieved from https:link.galegroup.com.proxy.library.carleton.ca/apps/doc/A471053911/AONE?u=ocul _carleton\&sid=AONE\&xid $=333 \mathrm{bfc} 2 \mathrm{a}$

Bodrova, E. (1997). Key Concepts of Vygostky’s Theory of Learning and Development. Journal of Early Childhood Teacher Education. 18 (2), 16-22.

Curran, T. \& Runswick-Cole, K. (2014) Disabled children's childhood studies: a distinct approach?, Disability \& Society, 29:10, 1617-1630, DOI:10.1080/09687599.2014.966187[[SHOULD COME AFTER CLARE]]

Clarke-Stewart, A. \& Parke, R.D. (2014). Social Development (2nd Ed.). Wiley. Frith, C. \& Frith, U. (2005). Theory of mind. Current Biology. 15(17), 644-

645.[[SHOULD COME AFTER CLARKE, A.]] https://dx-doi-org.proxy.library.carleton.ca/10.1016/j.cub.2005.08.041

Clarke, A., Flewitt, R., Hammersley, M., \& Robb, M. (2014) Understanding Research with Children and Young People. Sage Publications. 2014. ISBN: 9781446274934

Clare, E. (2017). Ideology of cure. In Brilliant imperfection: Grappling with cure (pp. 5-17). Durham: Duke University Press.

Glenn, N. M., Knight, C. J., Holt, N. L., \& Spence, J. C. (2013). Meanings of play among children. Childhood, 20(2), 185-199. https://doi.org/10.1177/0907568212454751

Goodley, D. \& Runswick-Cole, K. (2010) Emancipating play: dis/abled children, development and deconstruction, Disability \& Society, 25:4, 499-512, DOI:

$10.1080 / 09687591003755914$ 
Kehily, M.J. (2013) Understanding Childhood: A Cross-disciplinary Approach. The Open University (No.2)

Logan, S., Feldner, S., Bogart, K., Goodwin, B., Ross, S., Gatena, M.,... Galloway, J. (2017). Toy-Based Technologies for Children with Disabilities Simultaneously Supporting SelfDirected Mobility, Participation, and Function: A Tech Report. Frontiers in Robotics and Al. Retrieved from https://link.galegroup.com.proxy.library.carleton.ca/apps/doc/a483744083/AONE?u=ocul _carleton\&sid=AONE\&xid=98c77eaf

OHCHR. (2002, November 18). United Nations Human Rights: The Office of the High Commissioner. Retrieved from The Convention on the Rights of the Child: https:/www.ohchr.org/en/professionalinterest/pages/crc.aspx

McGuire, A. \& Michalko, R. (2011). Minds Between Us: Autism, mindblindness and the uncertainty of communication. Education and Philosophy Theory, 43(2), 162-177. DOI:10.1111/j.1469-5812.2009.00537.x

Nguyen, X. T. (2015). "Policy, power, and the paradigm shift of inclusion". The Journey to Inclusion: Studies in inclusive education. (pp. 49-87). Rotterdam, The Netherlands: Sense Publishers.

Nguyen, X. T., Mitchell, C., de Lange, N., \& Fritsch, K. (2015). Engaging girls with disabilities in Vietnam: making their voices count. Disability \& Society, 30(5), 773-787.

Thompson, G.A., Shanahan, E.C., \& Gordon, I. (2019). The Role of Music-Based Parent-Child Play Activities in Supporting Social Engagement with Children on the Autism Spectrum: A Content Analysis of Parent Interviews, Nordic Journal of Music Therapy, 28:2, 108130, DOI: 10.1080/08098131.2018.1509107

Visentin, I. (2018). Understanding the Structure of The Kindergarten Program. Retrieved from https://isabellavisentin.wordpress.com/ 